\title{
Triamcinolone acetonide induces sterile endophthalmitis in patients with intermediate uveitis: A case report series
}

\author{
MARIUS CRISTIAN ȘUȚA ${ }^{1 *}$, OLIMPIU LADISLAU KARANCSI ${ }^{2 *}$, OVIDIU MUȘAT $^{3}$, NICOLAE BALICA $^{4}$, \\ IASMINA YASAR $^{5}, \operatorname{COSMIN~ROȘCA}^{6}$, SIMONA STANCA $^{7}$ and DIANA-MARIA DĂRĂBUŞ ${ }^{1 *}$ \\ Departments of ${ }^{1}$ Ophthalmology and ${ }^{2}$ Oral Implantology and Prosthetic Restorations on Implants, \\ 'Victor Babeş' University of Medicine and Pharmacy, 300041 Timişoara; ${ }^{3}$ Department of Ophthalmology, \\ 'Dr. Carol Davila' Central Military Emergency University Hospital, 010825 Bucharest; \\ ${ }^{4}$ Department of ENT, 'Victor Babeş' University of Medicine and Pharmacy; ${ }^{5}$ Department of Ophthalmology, \\ Timişoara County Emergency Clinical Hospital, 300041 Timişoara; ${ }^{6}$ Department of Ophthalmology, \\ Oculens Clinic, 400501 Cluj-Napoca; 7 Department of Pediatrics, 'Carol Davila' \\ University of Medicine and Pharmacy, 020021 Bucharest, Romania
}

Received April 21, 2020; Accepted May 22, 2020

DOI: $10.3892 /$ etm.2020.8883

\begin{abstract}
Due to their anti-inflammatory, antiangiogenic and antiedematous properties, corticosteroids have been commonly used in the treatment of retinal diseases. Intravitreal administration of steroids offers the maximal drug efficacy and the lowest risk of systemic side effects. The authors report three cases of presumed sterile endophthalmitis induced by triamcinolone acetonide (TA) in three eyes with intermediate non-infectious uveitis. Each patient received a single intravitreal injection of TA of $4 \mathrm{mg}$. Because of the intense vitreous inflammatory reaction, retina examination and the optical coherence tomography could not be performed, although vitreous opacities were observed on the ocular ultrasound. The dense vitreous opacity is a defining factor, the anterior segment inflammation is mild to moderate and a hypopyon is present, which may be a sterile inflammatory reaction or the triamcinolone material itself. In cases of sterile endophthalmitis, the visual acuity increases progressively as the intraocular inflammation diminishes. Local treatment with topical antibiotics, prednisolone acetate and cycloplegic eyedrops is recommended to control the inflammatory reaction.
\end{abstract}

Correspondence to: Dr Olimpiu Ladislau Karancsi, Department of Oral Implantology and Prosthetic Restorations on Implants, 'Victor Babeş' University of Medicine and Pharmacy, Piaţa Eftimie Murgu 2, 300041 Timişoara, Romania

E-mail: olilk@yahoo.com

${ }^{*}$ Contributed equally

Key words: triamcinolone acetonide, sterile endophthalmitis, intermediate uveitis, vitreous haze, intravitreal steroids

\section{Introduction}

Corticosteroids can effectively control intraocular inflammation in patients with uveitis. Intraocular inflammation in uveitis causes vitreous opacity, retinal exudates, retinal haemorrhages, serous detachment, retinal neovascularization and cystoid macular edema $(1,2)$. Corticosteroids have been used since 1950 for the treatment of ocular inflammatory diseases (3). They have anti-inflammatory, antiangiogenic, and anti-permeability properties that make them a viable therapeutic option for a range of posterior segment diseases. The reduction of exudation, the stabilization of the blood-retinal barrier and the downregulation of inflammatory stimuli are among the main effects of steroids, even though the specific mechanisms remain unexplained. Steroids act by induction of proteins called lipocortins, in particular phospholipase A2. The proteins have multiple roles, such as the reduction of leukocyte chemotaxis, the control of biosynthesis, and the inhibition of arachidonic acid release from the phospholipid membrane. The arachidonic acid represents the most important precursor of potent inflammatory cell mediators, such as prostaglandins and leukotrienes. This regulation influences the expression of vascular endothelial growth factors (VEGF), inhibits pro-inflammatory genes, such as tumor necrosis factor-alpha (TNF- $\alpha$ ) and other inflammatory chemokines, and induces the expression of anti-inflammatory factors, such as pigment-derived growth factor (PEDF) $(4,5)$. Moreover, steroids seem to reduce the expression of matrix metalloproteinases (MMPs) and to downregulate intercellular adhesion molecule 1 (ICAM-1) on choroidal endothelial cells (6).

Several routes of administration have been considered for the treatment of various ocular diseases. Direct injection through the pars plana leads the steroids to the vitreous cavity. Many authors have suggested and reported that local intravitreal delivery of steroids inhibits proliferation of cells, intraocular inflammation and neovascularization (7). 
By using the intravitreal delivery method, the adverse systemic side effects of steroids are avoided. Intravitreal steroid path bypasses the blood-retinal barrier, leading to a more concentrated dose of steroids for a longer period of time. Considering the autoimmune nature of uveitis, patients should be tested for associated diseases before administering intraocular steroids (8-12). In order to exclude an infectious cause of uveitis, general examination and blood tests should be performed (13-18).

Triamcinolone acetonide (TA) belongs to the glucocorticoid family. It is a synthetic steroid with a fluorine in the ninth position and it is the most used steroid agent for the treatment of several retinal conditions (19). TA has an anti-inflammatory potency five times higher than hydrocortisone, with a tenth of the sodium-retaining potency. Its presentation form is a white colored crystalline powder insoluble in water, which explains its prolonged duration of action (20). Its therapeutic effects last approximately three months after $4 \mathrm{mg}$ intravitreal TA injection (21). A longer anti-inflammatory effect can be obtained with slow-release intravitreal dexamethasone implants, but it is also associated with a higher complication rate (cataract formation, elevated intraocular pressure, retinal detachment) (22). In some cases, the intraocular pressure can become refractory to treatment and very difficult to manage $(23,24)$.

\section{Case reports}

The authors report three cases where TA induced presumed sterile endophthalmitis in three eyes with intermediate uveitis. All three patients presented decreased visual acuity, blurry vision and floaters in the right eye. A baseline clinical examination was performed, including best-corrected visual acuity (BCVA), biomicroscopy of the anterior pole, intraocular pressure (IOP) and ocular ultrasound. Fundus examination and optical coherence tomography could not be performed because of the vitreous haze.

Case 1: 18-year-old female, BCVA right eye $=0.4(20 / 50)$, left eye $=1(20 / 20)$, IOP $=16 \mathrm{mmHg}$, normal aspect of the anterior pole, vitreous haze evenly localized of $3+$, corresponding to moderate inflammation (25). The inflammatory reaction was observed on the ocular ultrasound (Fig. 1A).

Case 2: 35-year-old male, BCVA right eye $=0.3(20 / 63)$, left eye $=1(20 / 20)$, IOP $=18 \mathrm{mmHg}$, normal aspect of the anterior pole, vitreous haze evenly localized of $4+$, corresponding to marked inflammation (25). The inflammatory reaction was observed on the ocular ultrasound (Fig. 2A).

Case 3: 42-year-old male, BCVA right eye $=0.1(20 / 200)$, left eye $=1(20 / 20)$, IOP $=12 \mathrm{mmHg}$, normal aspect of the anterior pole, vitreous haze evenly localized of $4+$, corresponding to marked inflammation (25). The ultrasound revealed the inflammatory reaction (Fig. 3A).

Each patient received a single intravitreal injection of $4 \mathrm{mg}$ TA. All injections were performed in the operating theatre. After topical disinfection with povidone-iodine, the sterile field and the lid speculum were applied. Local anesthesia with $0.4 \%$ oxybuprocaine drops was performed and local antibiotic drops were spread on. Injections were performed using 30 gauge needles through the inferotemporal pars plana, $4 \mathrm{~mm}$ from the limbus.
The present study was approved by the local Ethics Committee of the 'Centrul Oftalmologic Prof. Dr. Munteanu' Clinic (Timisoara, Romania). Signed written informed consents were obtained from the patients. All patients expressed in writing, prior to the treatment, their informed consent to receive intraocular treatment with triamcinolone acetonide.

\section{Results and Discussion}

After $24 \mathrm{~h}$, each of the patients came to our clinic and reported a decline in their visual acuity. After performing the ocular examinations, we concluded that all three patients had developed an acute sterile inflammatory reaction to TA, called sterile endophthalmitis, in their right eye.

Case 1: $24 \mathrm{~h}$ after the injection, BCVA right eye = $0.1(20 / 200)$, left eye $=1(20 / 20)$, normal IOP, anterior chamber flare $2+$, vitreous haze evenly localized of $4+$, corresponding to marked inflammation (25). The increased inflammatory reaction was also observed on the ultrasound (Fig. 1B).

Case 2: $24 \mathrm{~h}$ after the injection, BCVA right eye = counting fingers, left eye $=1(20 / 20)$, normal IOP, anterior chamber cells $3+$, vitreous haze evenly localized of $5+$, corresponding to severe inflammation (25). The increased inflammatory reaction was also observed on the ocular ultrasound (Fig. 2B).

Case 3: $24 \mathrm{~h}$ after the injection, BCVA right eye $=$ hand motion, left eye $=1(20 / 20)$, normal IOP, anterior chamber $0.2 \mathrm{~mm}$ pseudo-hypopyon, vitreous haze evenly localized of $5+$, corresponding to severe inflammation (25). The increased inflammatory reaction was also noted on the ultrasound (Fig. 3B).

All patients received local treatment with topical antibiotics, prednisolone acetate and cycloplegic eye drops; the vitreous inflammation resolved within 3 weeks in the first case and within 4 weeks in the other two cases. Our conclusion that these were cases of sterile, rather than infectious endophthalmitis was based on the resolution of the inflammation without the use of intravitreal antibiotics.

The causes of sterile endophthalmitis are not entirely understood. Some authors have suggested that the contamination of triamcinolone vials with endotoxins might be a possible cause, but studies performed on vials of triamcinolone showed no endotoxins $(26,27)$. Other researchers have mentioned a toxic effect of the triamcinolone itself, as well as the preservatives present in the vial (benzyl alcohol, polysorbate 80 and carboxymethylcellulose sodium) (28).

In a previous report, Lam et al (29) debated the issue of whether sterile endophthalmitis after intravitreal triamcinolone injection is a result of the preservatives contained in the triamcinolone suspension. In both cases described in this study, patients were injected with preservative-free triamcinolone and they developed presumed non-infectious endophthalmitis despite the absence of preservatives. The situation was similar to ours, since we used preservative-free triamcinolone in all eyes. Allergic reactions to triamcinolone have been described, but they were most likely due to preservatives (30).

There are two kinds of potential complications of intravitreal corticosteroid treatment: one is steroid-related and 

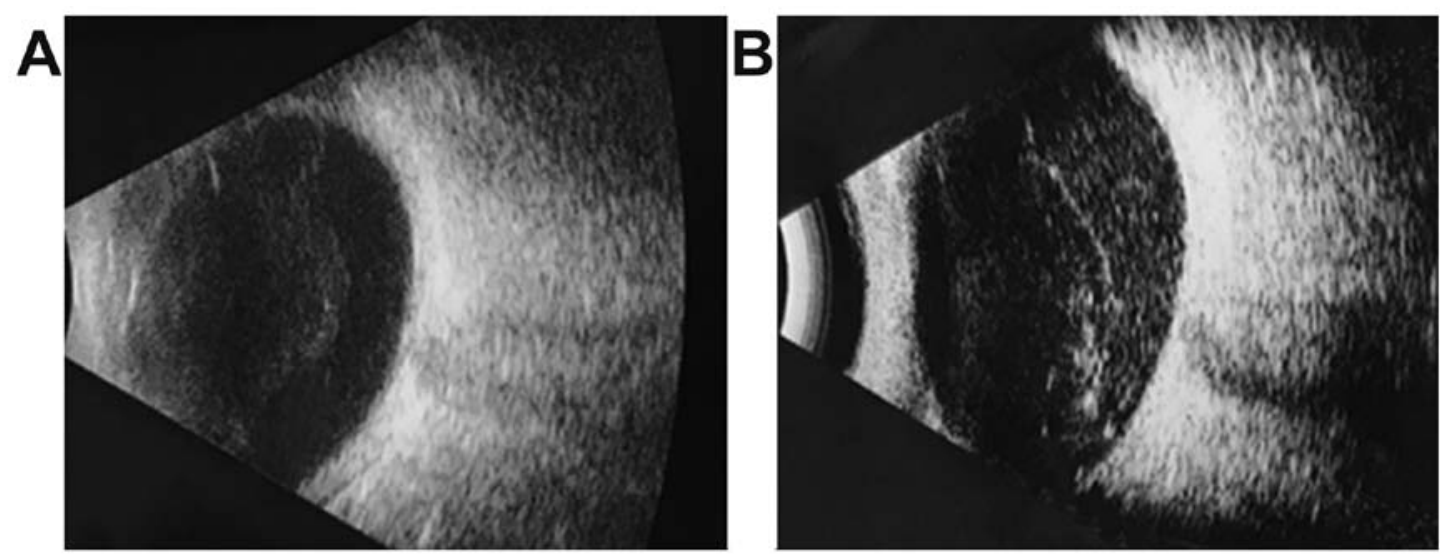

Figure 1. Case 1, ultrasound aspect of the right eye. (A) Before intraocular treatment. (B) One day after the intraocular treatment.
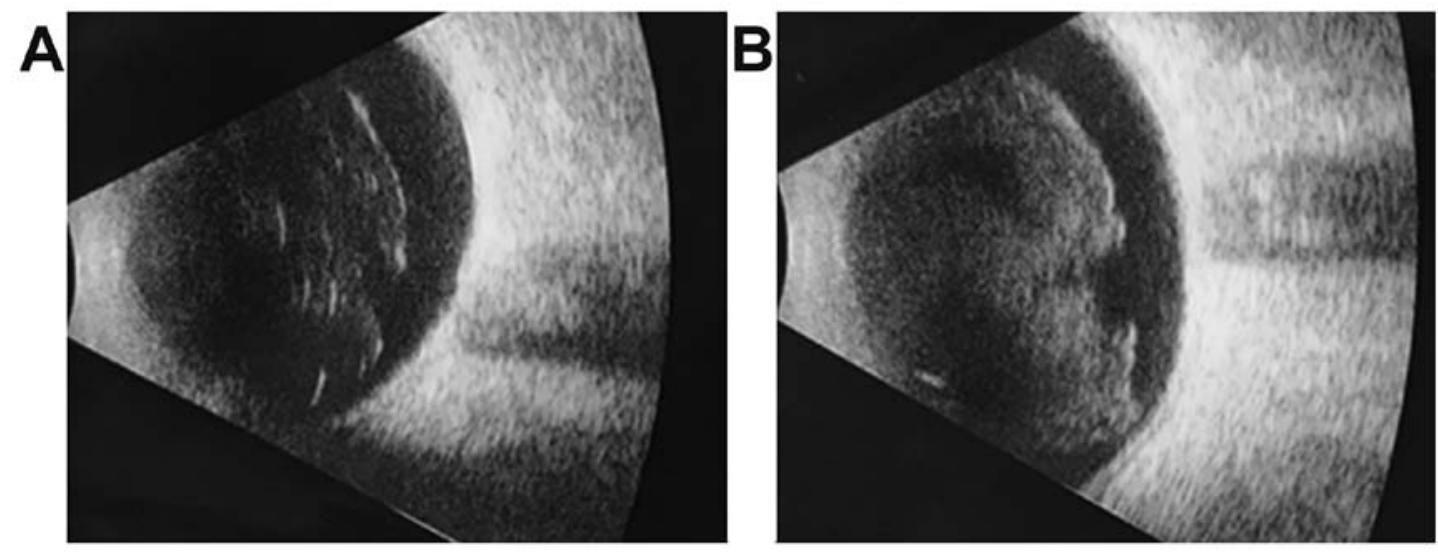

Figure 2. Case 2, ultrasound aspect of the right eye. (A) Before intraocular treatment. (B) One day after the intraocular treatment.
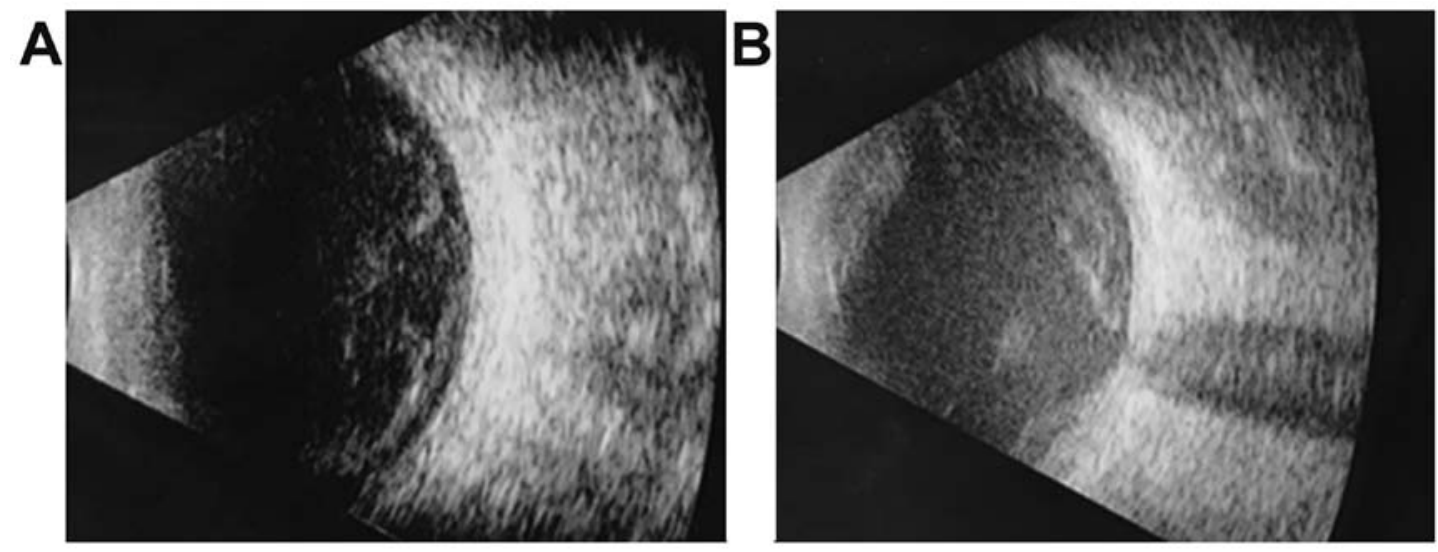

Figure 3. Case 3, ultrasound aspect of the right eye. (A) Before intraocular treatment. (B) One day after the intraocular treatment.

the other one is injection-related adverse effects. Cataract formation and an intraocular pressure increase refer to steroid-related side effects. Injection-related adverse effects include infectious endophthalmitis, sterile endophthalmitis and retinal detachment (31).

In conclusion, the severe inflammatory reaction, named sterile endophthalmitis, which appears after the intravitreal administration of triamcinolone in patients with uveitis, seems to occur mainly in the context of the off-label use of anti-inflammatory drugs that have not been approved for intravitreous use, most cases presenting a painless and acute vision loss. If the ophthalmologist is not sure about the sterile origin of the inflammation, this complication must be treated as an acute endophthalmitis because of the severe visual outcome of this intraocular infection without antibiotic therapy. The aetiology of sterile endophthalmitis, regardless of the intravitreous 
drug used, remains uncertain and a multifactorial origin must be considered.

\section{Acknowledgements}

Professional editing, linguistic and technical assistance performed by Irina Radu, Individual Service Provider, certified translator in Medicine and Pharmacy (certificate credentials: Series E no. 0048).

\section{Funding}

No funding was received.

\section{Availability of data and materials}

All data generated or analyzed during the study are included in this published article.

\section{Authors' contributions}

MCS conceived and designed the study, and was responsible for the acquisition of the data. OLK, NB and SS were involved in the design of the study and revised the manuscript. OM, CR, IY and DMD were also involved in the conception and design of the study, and revised the manuscript. All authors read and approved the final manuscript.

\section{Ethics approval and consent to participate}

The study was approved by the local Ethics Committee of the 'Centrul Oftalmologic Prof. Dr. Munteanu' Clinic (Timisoara, Romania).

\section{Patient consent for publication}

Signed written informed consents were obtained from the patients. All patients expressed in writing, prior to the treatment, their informed consent to receive intraocular treatment with triamcinolone acetonide.

\section{Competing interests}

The authors declare that they have no competing interests.

\section{References}

1. Oh-i K, Keino H, Goto H, Yamakawa N, Murase K, Usui Y, Kezuka T, Sakai J, Takeuchi M and Usui M: Intravitreal injection of Tacrolimus (FK506) suppresses ongoing experimental autoimmune uveoretinitis in rats. Br J Ophthalmol 91: 237-242, 2007.

2. Stanca HT, Suvac E, Munteanu M, Jianu DC, Motoc AGM, Roşca GC and Boruga O: Giant cell arteritis with arteritic anterior ischemic optic neuropathy. Rom J Morphol Embryol 58: 281-285, 2017.

3. Nachod GR: ACTH and cortisone in ocular disease. J Am Med Womens Assoc 6: 453-455, 1951.

4. Sarao V, Veritti D, Boscia F and Lanzetta P: Intravitreal steroids for the treatment of retinal diseases. ScientificWorldJournal 2014: 989501, 2014.

5. Umland SP, Nahrebne DK, Razac S, Beavis A, Pennline KJ, Egan RW and Billah MM: The inhibitory effects of topically active glucocorticoids on IL-4, IL-5, and interferon- $\gamma$ production by cultured primary $\mathrm{CD} 4^{+} \mathrm{T}$ cells. J Allergy Clin Immunol 100 511-519, 1997.
6. Floman $\mathrm{N}$ and Zor U: Mechanism of steroid action in ocular inflammation: Inhibition of prostaglandin production. Invest Ophthalmol Vis Sci 16: 69-73, 1977.

7. Machemer R, Sugita G and Tano Y: Treatment of intraocular proliferations with intravitreal steroids. Trans Am Ophthalmol Soc 77: 171-180, 1979.

8. Munteanu M, Giuri S, Roșca C, Boruga O and Creţu O: Multifocal choroidal metastases from thyroid carcinoma: A case report. Chirurgia (Bucur) 108: 268-272, 2013.

9. Munteanu M, Munteanu G, Zolog I, Giuri S, Coviltir V, Stanca $\mathrm{H}$ and Cretu O: Ocular decompression retinopathy after combined deep sclerectomy and trabeculotomy. Klin Monbl Augenheilkd 229: 830-831, 2012 (In German).

10. Grigore O, Mihailescu AI, Solomon I, Boda D and Caruntu C: Role of stress in modulation of skin neurogenic inflammation. Exp Ther Med 17: 997-1003, 2019.

11. Ilie MA, Caruntu C, Lixandru D, Tampa M, Georgescu SR, Constantin MM, Constantin C, Neagu M, Zurac SA and Boda D: In vivo confocal laser scanning microscopy imaging of skin inflammation: Clinical applications and research directions. Exp Ther Med 17: 1004-1011, 2019.

12. Ilie MA, Caruntu C, Tampa M, Georgescu SR, Matei C, Negrei C, Ion RM, Constantin C, Neagu M and Boda D: Capsaicin: Physicochemical properties, cutaneous reactions and potential applications in painful and inflammatory conditions. Exp Ther Med 18: 916-925, 2019.

13. Stanca S, Ulmeanu CE, Stanca HT and Iovanescu G: Clinical features in toxic coma in children. Exp Ther Med 18: 5082-5087, 2019.

14. Stanca HT, Munteanu M, Jianu DC, Motoc AGM, Tăbăcaru B, Stanca S, Ungureanu E, Boruga VM and Preda MA: New perspectives in the use of laser diode transscleral cyclophotocoagulation. A prospective single center observational cohort study. Rom J Morphol Embryol 59: 869-872, 2018.

15. Boruga O, Balasoiu AT, Giuri S, Munteanu M, Stanca HT, Iovanescu G and Preda MA: Caruncular late-onset junctional nevus: Apropos of an anatomo-clinical observation. Rom J Morphol Embryol 58: 1461-1464 2017.

16. Stanca HT, Petrović Z and Munteanu M: Transluminal Nd: YAG laser embolysis - a reasonable method to reperfuse occluded branch retinal arteries. Vojnosanit Pregl 71: 1072-1077, 2014.

17. Ghiţă MA, Căruntu C, Rosca AE, Căruntu A, Moraru L, Constantin C, Neagu M and Boda D: Real-time investigation of skin blood flow changes induced by topical capsaicin. Acta Dermatovenerol Croat 25: 223-227, 2017.

18. Boda D, Negrei C, Nicolescu F and Badalau C: Assessment of some oxidative stress parameters in methotrexate treated psoriasis patients. Farmacia 62: 704-710, 2014.

19. Sarao V, Veritti D and Lanzetta P: Triamcinolone Acetonide for the treatment of diabetic macular oedema. Eur Ophthalmic Rev 6: 28-33, 2012

20. Beer PM, Bakri SJ, Singh RJ, Liu W, Peters GB III and Miller M: Intraocular concentration and pharmacokinetics of triamcinolone acetonide after a single intravitreal injection. Ophthalmology 110: 681-686, 2003.

21. Inoue M, Takeda K, Morita K, Yamada M, Tanigawara Y and Oguchi Y: Vitreous concentrations of triamcinolone acetonide in human eyes after intravitreal or subtenon injection. Am J Ophthalmol 138: 1046-1048, 2004.

22. Munteanu M and Rosca C: Repositioning and follow-up of intralenticular dexamethasone implant. J Cataract Refract Surg 39: 1271-1274, 2013.

23. Preda MA, Popa G, Karancsi OL, Musat O, Popescu SI, Munteanu M and Popa Z: Effectiveness of subconjunctival bevacizumab associated with a laser-based procedure in the treatment of neovascular glaucoma. Farmacia 66: 621-626, 2018.

24. Preda MA, Karancsi OL, Munteanu M and Stanca HT: Clinical outcomes of micropulse transscleral cyclophotocoagulation in refractory glaucoma - 18 months follow-up. Lasers Med Sci: Jan 14, 2020 (Epub ahead of print).

25. Zierhut M, Deuter C and Murray PI: Classification of uveitis current guidelines. Eur Ophthalmic Rev: 77-78, 2011. http://doi. org/10.17925/EOR.2007.00.00.77

26. Jonisch J, Lai JC, Deramo VA, Flug AJ and Fastenberg DM: Increased incidence of sterile endophthalmitis following intravitreal preserved triamcinolone acetonide. $\mathrm{Br} \mathrm{J}$ Ophthalmol 92: 1051-1054, 2008. 
27. Roth DB, Chieh J, Spirn MJ, Green SN, Yarian DL and Chaudhry NA: Noninfectious endophthalmitis associated with intravitreal triamcinolone injection. Arch Ophthalmol 121: 1279-1282, 2003.

28. Yeung CK, Chan KP, Chan CKM, Pang CP and Lam DSC: Cytotoxicity of triamcinolone on cultured human retinal pigment epithelial cells: Comparison with dexamethasone and hydrocortisone. Jpn J Ophthalmol 48: 236-242, 2004.

29. Lam A, Garg SJ, Spirn MJ, Fineman MS and Sivalingam A: Sterile endophthalmitis following intravitreal injection of preservative-free triamcinolone acetonide. Retin Cases Brief Rep 2: 228-230, 2008.
30. Montoro J, Valero A,Elices A, Rubira N, Serra-Baldrich E, Amat P and Malet A: Anaphylactic shock after intra-articular injection of carboxymethylcellulose. Allergol Immunopathol (Madr) 28: 332-333, 2000.

31. Scott IU and Flynn HW Jr: Reducing the risk of endophthalmitis following intravitreal injections. Retina 27: 10-12, 2007.

This work is licensed under a Creative Commons Attribution-NonCommercial-NoDerivatives 4.0 International (CC BY-NC-ND 4.0) License. 